Check for updates

Cite this: RSC Adv., 2019, 9, 5218

\title{
Effects of dairy manure biochar on adsorption of sulfate onto light sierozem and its mechanisms
}

\begin{abstract}
Baowei Zhao, (D) Huan Xu, Fengfeng Ma, Tao Zhang and Xujun Nan
The adsorption of nitrogen and phosphorous nutrients on biochar and even biochar-soil mixtures was investigated. However, the situation of sulfur was not very clear. Here, sulfate $\left(\mathrm{SO}_{4}{ }^{2-}\right)$ adsorption onto dairy manure biochar obtained at $700{ }^{\circ} \mathrm{C}$ (DMBC700), soil (light sierozem) and a $1: 9(\mathrm{w} / \mathrm{w})$ biochar-soil mixture (DMBC700-soil) was investigated using batch experiments. The contact time, sulfate concentration, and solution $\mathrm{pH}$ value were chosen as the main factors; their effects on sulfate adsorption were tested, and the kinetics and isotherms were also investigated. Fourier transform infrared (FTIR) and X-ray diffraction (XRD) spectroscopies were used to characterize DMBC700 and soil before and after adsorbing sulfate, respectively, and to analyze the mechanisms of adsorption. The results showed that the adsorption kinetics were well described by the pseudo-second-order model, whereas the Langmuir and Freundlich models fitted well with the equilibrium data. DMBC700 modification did not increase the adsorption capacity of light sierozem for sulfate. When the $\mathrm{pH}$ values of the initial solution were increased, all the adsorption capacities of sulfate onto DMBC700, light sierozem and light sierozem with $\mathrm{DMBC700}$ decreased. The electrostatic interaction was the main force for the adsorption of sulfate onto DMBC700, whereas both electrostatic interaction and formation of poorly soluble $\mathrm{CaSO}_{4}$ were the main forces for adsorption of sulfate onto light sierozem. DMBC700 was found to have negative effect on sulfate adsorption onto light sierozem.
\end{abstract}

Received 28th October 2018

Accepted 29th January 2019

DOI: $10.1039 / \mathrm{c} 8 \mathrm{ra0} 8916 \mathrm{~g}$

rsc.li/rsc-advances
However, a few limiting and even negative effects of biochars to fix $\mathrm{NO}_{2}{ }^{-}, \mathrm{NO}_{3}{ }^{-}$, and $\mathrm{PO}_{4}{ }^{3-}$ were reported. ${ }^{13-18}$ Comparatively, to the best of our knowledge, there are only few reports concerning the effects of biochars on sulfur adsorption and retention in soils. ${ }^{19}$ The situation of sulfur is not very clear because the adsorptive properties of biochar are largely dependent on the biomass feed type and pyrolysis conditions.

Thus, we prepared a biochar from dairy manure at $700{ }^{\circ} \mathrm{C}$ and selected light sierozem as the tested soil. Batch experiments were conducted to investigate sulfate adsorption onto biochar, soil, and biochar-soil mixtures. We aimed to determine the effects of dairy manure biochar on the adsorption of sulfate onto light sierozem and its mechanisms.

\section{Materials and methods}

Chemicals and materials

Sodium sulfate with analytical purity was obtained from Tianjin Guangfu Fine Chemical Institute, China. Deionized water was used in all experiments.

The dairy manure was collected from a farm in Anning District, Lanzhou City, China. The manure was air-dried, crushed by a grinder and passed through an 80 mesh sieve. The sample was put into a crucible, compacted, and covered with a lid. Then, the sample was heated in a muffle furnace at $700{ }^{\circ} \mathrm{C}$ for $6 \mathrm{~h}$ to pyrolyze the manure. After cooling to room
School of Environmental and Municipal Engineering, Lanzhou Jiaotong University, No. 88, West Anning Road, Lanzhou 730070, Gansu, P. R. China.E-mail: zhbw2001@sina. com; baowei.zhao@yahoo.com; Fax: +86-931-4956017; Tel: +86-931-4938017 
temperature, the obtained biochar was passed through an 80 mesh sieve and labelled as DMBC700. The $\mathrm{pH}$ value of DMBC700 was measured using a pH meter (PHS-3C, Shanghai Electronic and Scientific Instrument Co., China) with $1: 2.5$ (w/ $\mathrm{w}$ ) suspension of the biochar in deionized water. The total $\mathrm{C}, \mathrm{H}$, $\mathrm{O}, \mathrm{N}$ and ash contents in biochar were determined with an elemental analyzer (Vario EL, Elementar, Germany), and the atomic ratios were calculated. Brunauer-Emmett-Teller (BET) surface area was obtained from $\mathrm{N}_{2}$ adsorption at $77 \mathrm{~K}$ using Quantachrome Autosorb-1 (Quantachrome, USA). The basic physical and chemical properties of biochar are as follows: $\mathrm{pH}$, 10.15; element composition (\%): C 45.86, H 0.52, O 12.51, N 1.08, ash 39.28; atomic ratios: $\mathrm{O} / \mathrm{C} 0.27, \mathrm{H} / \mathrm{C} \mathrm{0.01,}(\mathrm{O}+\mathrm{N}) / \mathrm{C} 0.30$; and specific surface area, $73.97 \mathrm{~m}^{2} \mathrm{~g}^{-1}$.

The light sierozem soil was sampled from the topsoil (0-20 $\mathrm{cm}$ ) in a farmland in Yuzhong County, Lanzhou City, Gansu Province, China. After removing the impurities, the soil was airdried, mixed thoroughly and passed through an 80 mesh sieve. The organic matter (OM) in the soil was analysed using the potassium dichromate oxidation method by a UV-1800 spectrophotometer (Shanghai Spectrum Instrument Co. Ltd., China). The $\mathrm{pH}$ value of the soil was measured on the $\mathrm{pH}$ meter with $1: 5(\mathrm{w} / \mathrm{w})$ suspension of soil in deionized water. Cation exchange capacity (CEC) was determined according to the calcium acetate method (China NY/T1121.5-2006). The efficient sulfur (ES) was extracted using $\mathrm{NaHCO}_{3}$ and determined using the barium sulfate turbidity method. The basic physical and chemical properties of soil are as follows: organic matter (OM), 14.12\%; pH, 7.97; cation exchange capacity (CEC), $5.65 \mathrm{cmol}$ $\mathrm{kg}^{-1}$; and efficient sulfur (ES), $36.7 \mathrm{mg} \mathrm{kg}^{-1}$.

\section{Batch adsorption}

The contact time, initial sulfate concentration and solution $\mathrm{pH}$ value were selected as the main factors, and batch adsorption experiments were conducted in the general process: a series of $0.1 \mathrm{~g}$ DMBC700, DMBC700-soil (1 : $9(\mathrm{w} / \mathrm{w})$ ) or soil were weighed into $50 \mathrm{~mL}$ flasks containing $20 \mathrm{~mL}$ sodium sulfate solution. The samples were then put into a reciprocating shaker (THZ82, Jiangsu Jintan Youlian Instrument Institute, China) and equilibrated for a certain period at $25{ }^{\circ} \mathrm{C}$. Then, the liquid-solid mixtures were filtered through a $0.45 \mu \mathrm{m}$ membrane, and the sulfate concentration in filtrate was determined; here, the filtered single DMBC700 or light sierozem soil after adsorption in $400 \mathrm{mg} \mathrm{L}^{-1}$ of sodium sulfate solution for $16 \mathrm{~h}$ at $25^{\circ} \mathrm{C}$ and pH 7 was air-dried and characterized by FTIR and XRD. The contact time, initial sulfate concentration and solution $\mathrm{pH}$ value were maintained as $20 \mathrm{~h}, 50 \mathrm{mg} \mathrm{L}^{-1}$ and 7 unless tested as a factor.

\section{FTIR and XRD characterization}

FTIR spectra were obtained in the range of $500-4000 \mathrm{~cm}^{-1}$ of wave number on an IR spectrometer (Nicolet Nexus 870, USA). XRD was conducted on an X-ray diffractometer (PANalytical $\mathrm{X}^{\prime}$ Pert Pro) over the $2 \theta$ range of $3-90^{\circ}$ at a rate of $1^{\circ} \cdot \mathrm{min}^{-1}$ with a step size of $0.02^{\circ}$.

\section{Analysis methods}

The indirect atomic absorbance spectrometry (AAS) method ${ }^{20}$ was used to determine the sulfate concentration on an atomic absorbance spectrometer (SP-3520AAC2T1, Shanghai Spectrum Instrument Company, China). The adsorbed amount of sulfate $\left(\mathrm{mg} \mathrm{g}^{-1}\right)$ was calculated from the difference between the initial and equilibrium sulfate concentrations $\left(\mathrm{mg} \mathrm{L}^{-1}\right)$, solution volume (L) and adsorbent mass $(\mathrm{g})$ in terms of the overall adsorbent mass. Nonlinear fitting was applied to obtain the regression parameters in kinetics and isotherm equations using OriginPro 8.0.

\section{Results and discussion}

\section{Effect of contact time and adsorption kinetics}

The effects of contact time on absorption amounts of sulfate onto DMBC700, soil and soil with DMBC700 are shown in Fig. 1. It can be seen from Fig. 1 that the adsorption rate is fast in the initial $2 \mathrm{~h}$, at which the adsorption amounts are 89.21, 84.84 and $83.89 \%$ of the equilibrium adsorption capacity. With increase in contact time, the adsorption amounts onto DMBC700, soil and soil with DMBC700 increased slightly and levelled off at about 3.65, 3.54 and $3.21 \mathrm{mg} \mathrm{g}^{-1}$, respectively. It was clear that the adsorption capacity of sulfate onto soil did not improve in the presence of $\mathrm{DMBC} 700$, indicating that DMBC700 may play a negative role in sulfate fixation after its considerable amendment into soils. $\mathrm{Li}$ et al. found that switchgrass and water oak biochars and biosolid biochar have limited and negative retention for $\mathrm{NO}_{2}{ }^{-}$and $\mathrm{NO}_{3}{ }^{-} \cdot{ }^{13}$ Liu et al. found that within a certain range of phosphate concentration in the equilibrium solution, the amount of phosphate adsorbed by three red soils decreased and the corresponding amount of phosphate desorbed increased with increasing amendment rate of rice straw biochar. ${ }^{14}$ The adsorption capacity of phosphate onto the engineered cow dung biochar (Mg-loaded) reached $345 \mathrm{mg} \mathrm{g}^{-1}$, which was significantly higher than those

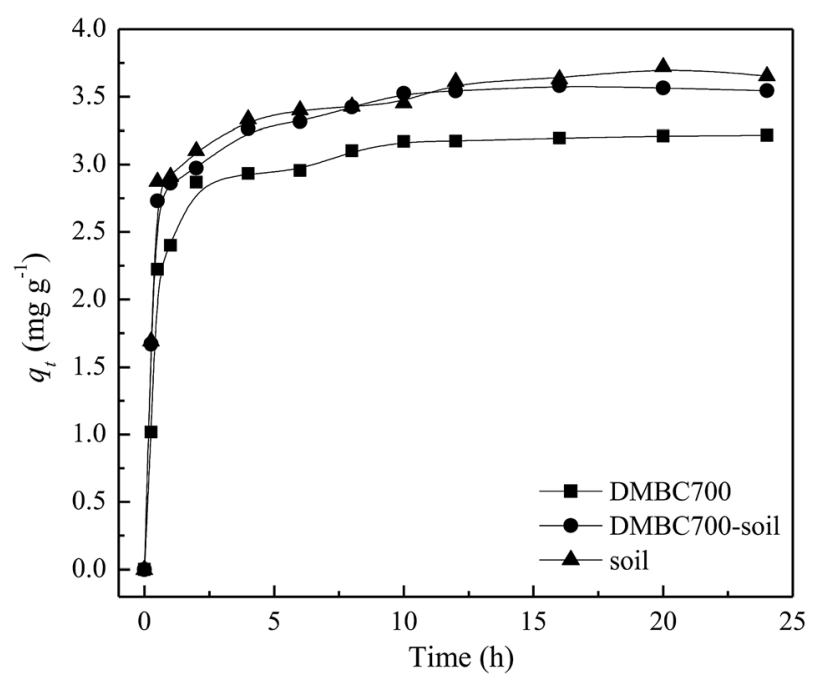

Fig. 1 Effect of time on sulfate adsorption onto DMBC700, soil and soil with $\operatorname{DMBC} 700\left(C_{0}=50 \mathrm{mg} \mathrm{L}^{-1}, \mathrm{pH}=7, T=25^{\circ} \mathrm{C}\right)$. 
previously obtained under the same initial $\mathrm{P}$ concentrations. ${ }^{\mathbf{1 2}}$ The adsorption capacities of biochars for anionic nutrients were largely different, which might be due to the biochar's surface components and properties.

Pseudo-first-order (1), pseudo-second-order (2), and Elovich (3) models were used to simulate the experimental kinetics, which can be expressed by the following equations:

$$
\begin{gathered}
\mathrm{d} q_{t} / \mathrm{d} t=k_{1}\left(q_{\mathrm{e}}-q_{t}\right) \\
\mathrm{d} q_{t} / \mathrm{d} t=k_{2}\left(q_{\mathrm{e}}-q_{t}\right)^{2} \\
\mathrm{~d} q_{t} / \mathrm{d} t=\alpha \exp \left(-\beta q_{t}\right)
\end{gathered}
$$

Here, $q_{t}\left(\mathrm{mg} \mathrm{g}^{-1}\right)$ and $q_{\mathrm{e}}\left(\mathrm{mg} \mathrm{g}^{-1}\right)$ are the adsorbed amounts of sulfate at time $t(\mathrm{~h})$ and at equilibrium, respectively; $k_{1}\left(\mathrm{~h}^{-1}\right)$ and $k_{2}\left(\mathrm{~g} \mathrm{mg}^{-1} \mathrm{~h}^{-1}\right)$ are the adsorption rate constants of pseudofirst-order and pseudo-second-order models, respectively, $\alpha$ (mg $\left.\mathrm{g}^{-1} \mathrm{~h}^{-1}\right)$ is the initial sorption rate, and $\beta\left(\mathrm{g} \mathrm{mg}^{-1}\right)$ is the desorption constant. The fitting parameters of kinetic models are listed in Table 1 . The $R^{2}$ values $(0.9426,0.9343$ and 0.9118 ) obtained from the pseudo-second-order model fitting for the adsorption of sulfate onto DMBC700, soil and soil with DMBC700 were higher than those of the pseudo-first-order and Elovich models. Moreover, the equilibrium adsorbed amounts of sulfate calculated from the pseudo-second-order model $\left(q_{\text {e,cal }}\right)$ were much closer to the experimental values shown in Fig. 1. This indicated that the pseudo-second-order model provides the best fit with the experimental data. Hafshejani et al. found a pseudo-second-order kinetic model, which could fit well with the experimental data for the adsorption of nitrate onto modified sugarcane bagasse biochar. ${ }^{8}$ Similar results were also reported by Takaya et al. for the adsorption of phosphate ions onto chars. ${ }^{10}$

\section{Effect of sulfate concentration and adsorption isotherms}

The relationships between the adsorption capacities of DMBC700, soil and soil with DMBC700 for sulfate and the equilibrium sulfate concentrations are shown in Fig. 2. The adsorption amounts of sulfate onto DMBC700, soil and soil with DMBC700 increased with the sulfate concentration. This might be due to the higher concentration gradients in the systems, which resulted in higher occupation of the reactive sorption sites. ${ }^{\mathbf{1 0 2 1}}$ Clearly, the adsorption amounts of sulfate

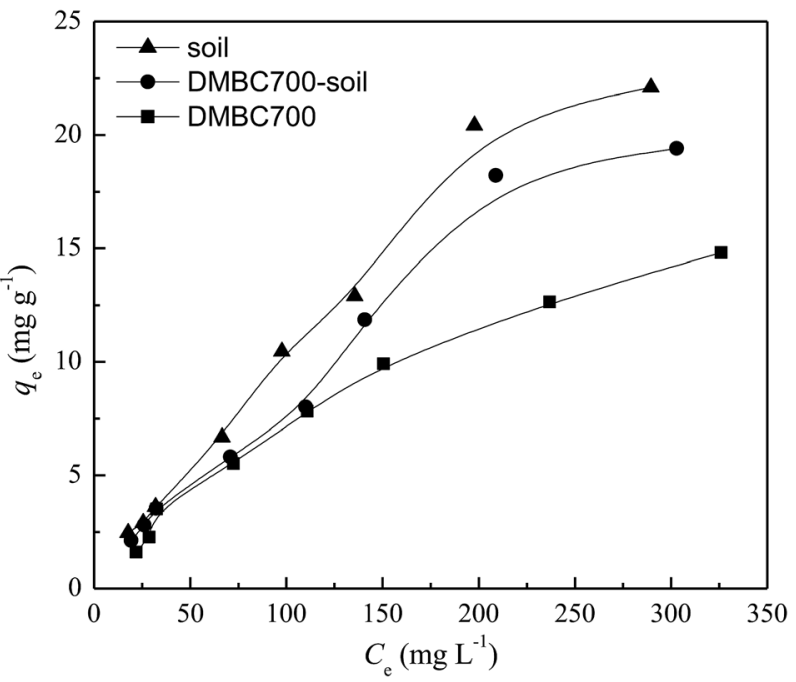

Fig. 2 Effect of equilibrium concentration on sulfate adsorption onto DMBC700, soil and soil with DMBC700 ( $\left.t=16 \mathrm{~h}, \mathrm{pH}=7, T=25^{\circ} \mathrm{C}\right)$.

onto soil were larger than those onto DMBC700 and soil with DMBC700.

Three models Langmuir (4), Freundlich (5), and Temkin (6) ${ }^{22}$ were used to fit the sulfate adsorption equilibrium described in Fig. 2:

$$
\begin{gathered}
q_{\mathrm{e}}=q_{\mathrm{m}} K_{\mathrm{L}} C_{\mathrm{e}} /\left(1+K_{\mathrm{L}} C_{\mathrm{e}}\right) \\
q_{\mathrm{e}}=K_{\mathrm{F}} C_{\mathrm{e}}^{1 / n} \\
q_{\mathrm{e}}=B \ln A C_{\mathrm{e}}
\end{gathered}
$$

Here, $q_{\mathrm{e}}$ is the equilibrium adsorption capacity of sulfate (mg $\left.\mathrm{g}^{-1}\right), C_{\mathrm{e}}$ is the equilibrium sulfate concentration in an aqueous solution $\left(\mathrm{mg} \mathrm{L}^{-1}\right), K_{\mathrm{L}}$ is the Langmuir constant $\left(\mathrm{L} \mathrm{mg}^{-1}\right), K_{\mathrm{F}}(\mathrm{mg}$ $\left.\mathrm{g}^{-1} \mathrm{~L} \mathrm{mg}\right)^{1 / n}$ is the Freundlich constant, $n$ (dimensionless) is the adsorption intensity factor, $q_{\mathrm{m}}$ is the maximum adsorption capacity $\left(\mathrm{mg} \mathrm{g}^{-1}\right), B$ is the equilibrium binding constant $(\mathrm{L}$ $\mathrm{mol}^{-1}$ ), and $A$ is a constant related to heat adsorption. The regression results are listed in Table 2 . According to the obtained $R^{2}$ values, sulfate adsorption onto DMBC700, soil and soil with DMBC700 could fit well with the Freundlich and Langmuir models. In some cases, it was found that the Langmuir model was better than the Freundlich one for fitting phosphate,,$^{\mathbf{9 1 1 , 2 1}}$ nitrate $^{\mathbf{8}}$ and ammonium ${ }^{\mathbf{1 3}}$ species on biochars,

Table 1 Kinetic parameters for sulfate adsorption onto DMBC700, soil and soil with DMBC700

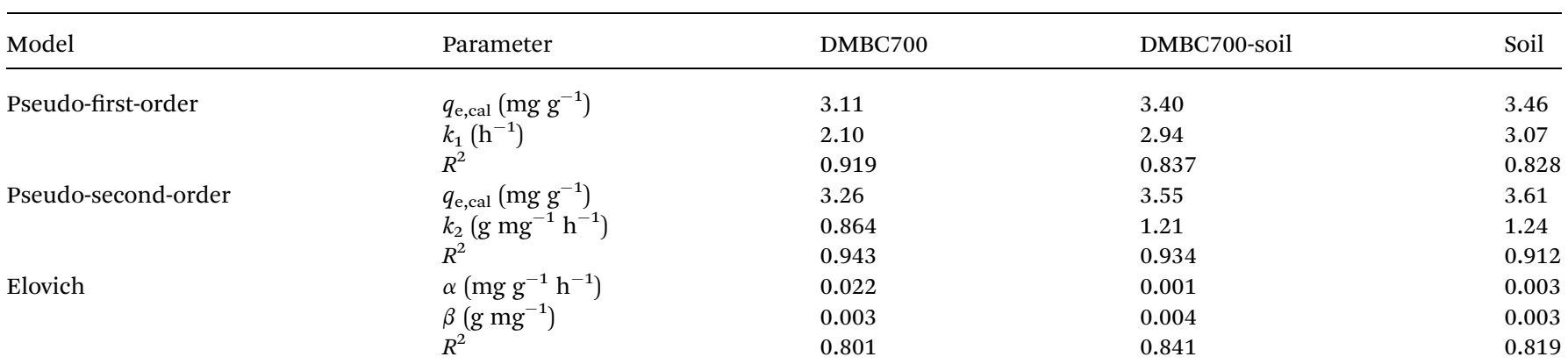


Table 2 Isotherm parameters for sulfate adsorption onto DMBC700, soil and soil with DMBC700

\begin{tabular}{lllll}
\hline Model & Parameter & DMBC700 & DMBC700-soil & Soil \\
\hline \multirow{2}{*}{ Langmuir } & $q_{\mathrm{e}, \text { cal }}\left(\mathrm{mg} \mathrm{g}^{-1}\right)$ & 78.1 & 78.4 & 83.0 \\
& $K_{\mathrm{L}}\left(\mathrm{L} \mathrm{mg}^{-1}\right)$ & 0.00087 & 0.00088 & 0.00096 \\
& $R^{2}$ & 0.960 & 0.978 & 0.986 \\
Freundlich & $K_{\mathrm{F}}\left(\mathrm{L} \mathrm{mg}^{-1}\right)$ & 0.219 & 0.121 & 0.144 \\
& $N$ & 1.41 & 1.17 & 1.18 \\
Temkin & $R^{2}$ & 0.942 & 0.975 & 0.981 \\
& $A\left(\mathrm{~L} \mathrm{mg}{ }^{-1}\right)$ & 0.039 & 0.034 & 0.033 \\
& $B$ & 5.01 & 6.78 & 7.77 \\
& $R^{2}$ & 0.971 & 0.923 & 0.913
\end{tabular}

while the Freundlich model was more suitable for fitting the adsorption of phosphate on several chars. ${ }^{\mathbf{1 0}}$ Liu et al. found that depending on the soil $\mathrm{pH}$, the Temkin isotherms for $\mathrm{P}$ sorption in low-pH soils revealed high $R^{2}$ values. ${ }^{14}$

\section{Effect of solution pH value and adsorption mechanisms}

Fig. 3 shows that the sulfate adsorption amounts change with the initial solution $\mathrm{pH}$ values. The adsorbed amounts of sulfate onto DMBC700, soil and soil with DMBC700 decreased gradually when the $\mathrm{pH}$ values increased from 2 to 12 . This might be attributed to the electrostatic interactions between sulfate and the charged sorbent surfaces. In general, the charges loaded on the soil particle surfaces are classified as variable and constant ones. The later derived from the isomorphous replacement in mineral formation is not affected by the change in $\mathrm{pH}$. However, the former arising from organic matters, metal oxides, hydrated metal oxides, etc. changes with the solution $\mathrm{pH}$ value, due to which the total charge of soil particle surfaces can be positive, zero or negative. ${ }^{23}$ Various functional groups on the surfaces of biochar may influence sorption by the nature of their surface charge. Similar to that observed for oxide surfaces, the charge on the functional groups may change depending upon the $\mathrm{pH}$ value

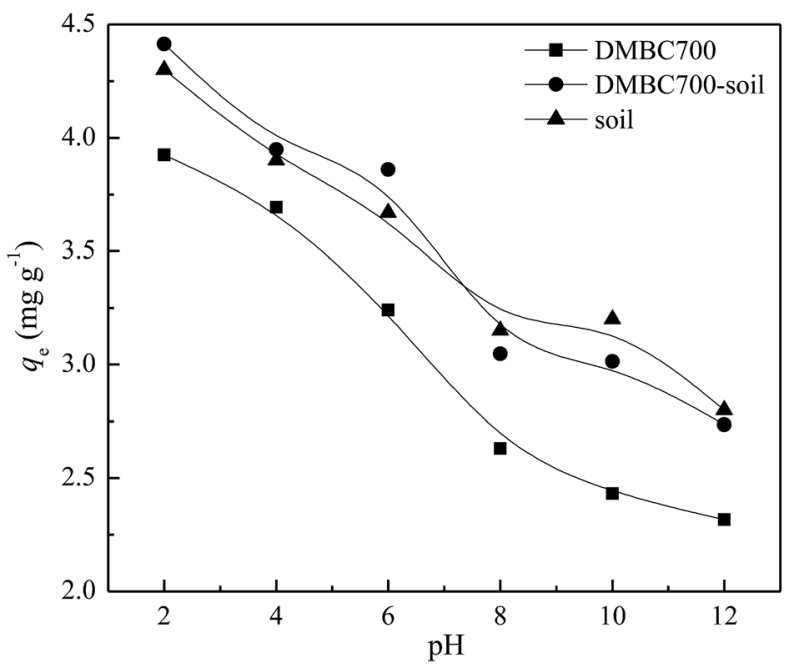

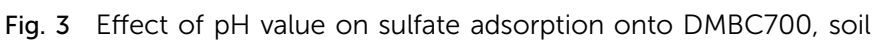
and soil with DMBC700 $\left(C_{0}=50 \mathrm{mg} \mathrm{L}^{-1}, t=16 \mathrm{~h}, T=25^{\circ} \mathrm{C}\right)$.

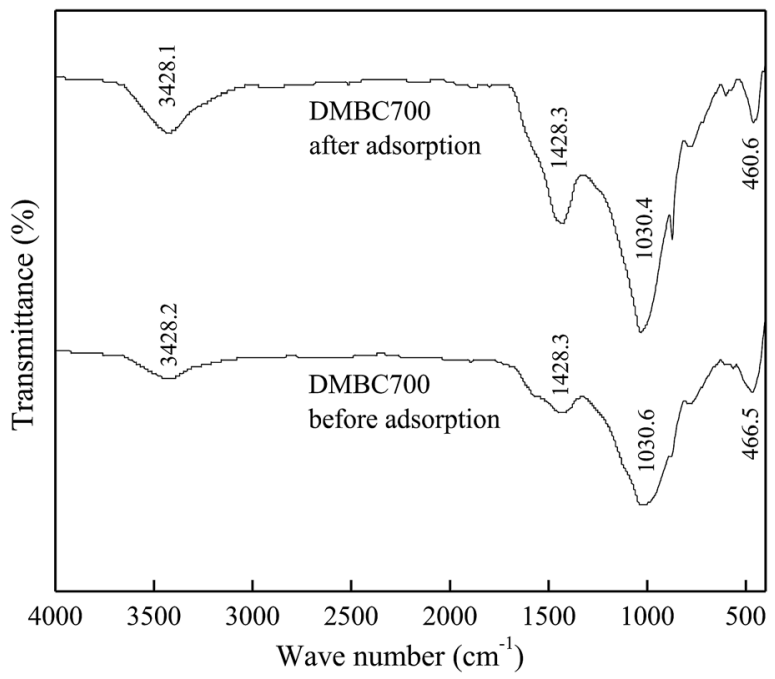

Fig. 4 FTIR spectra of DMBC700 before and after adsorption.

of the solution, thus affecting sorption behaviour., ${ }^{\mathbf{4 2 4}}$ At lower $\mathrm{pH}$ values, more positively charged sites are present on DMBC700 and soil surfaces. Thus, more sulfate ions can be adsorbed. ${ }^{25,26} \mathrm{At}$ $\mathrm{pH} 2$, the adsorbed amounts of sulfate on DMBC700, soil and soil with DMBC700 were 3.93, 4.30 and $4.41 \mathrm{mg} \mathrm{g}^{-1}$, respectively. With increase in $\mathrm{pH}$, the soil and DMBC700 surfaces became more negatively charged and thus, the adsorbed amounts of sulfate decreased. Meanwhile, the reduction in adsorbed amounts of sulfate was partially attributed to the competition of hydroxyl ion adsorption onto soil and DMBC700 with the increase in $\mathrm{pH}$. At $\mathrm{pH} 12$, the adsorbed amounts of sulfate on DMBC700, soil and soil with DMBC700 were 2.31, 2.80 and $2.73 \mathrm{mg} \mathrm{g}^{-1}$, respectively. A similar trend was also found in recent reports for nitrate adsorption onto sugarcane bagasse biochar ${ }^{8}$ and phosphate adsorption ${ }^{\mathbf{1 1}}$ onto chars.

The FTIR spectra of DMBC700 and soil before and after adsorption of sulfate are shown in Fig. 4 and 5, respectively. It is

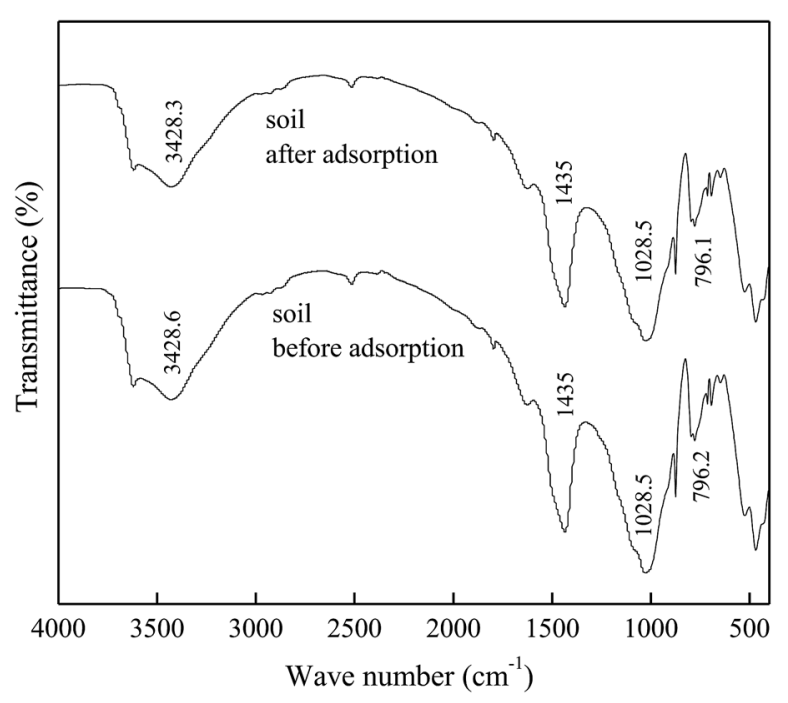

Fig. 5 FTIR spectra of soil before and after adsorption. 


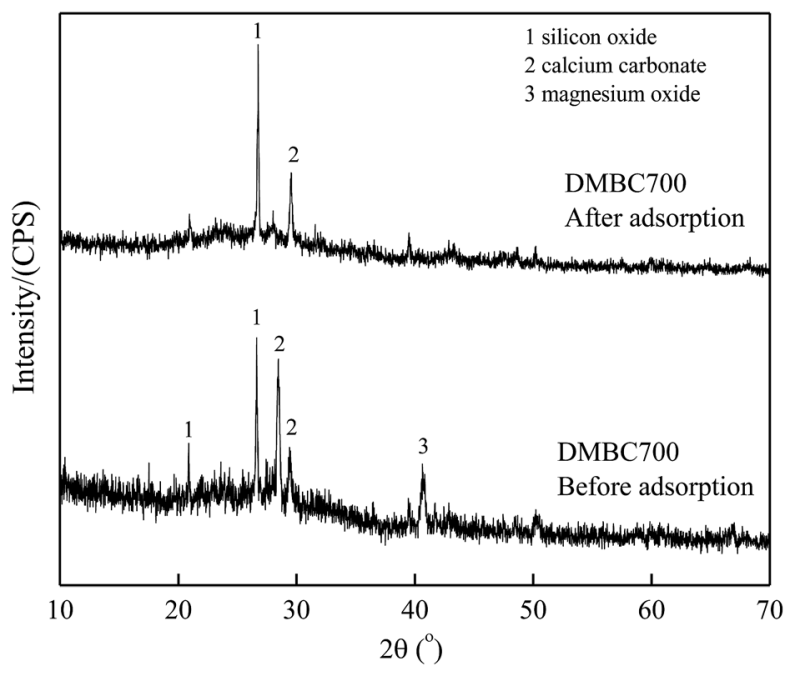

Fig. 6 XRD spectra of DMBC700 before and after adsorption.

found that the main transmittance peak intensity and the corresponding wave number did not change significantly. It was indicated that the sulfate adsorption was not due to the interaction between the surface functional groups and sulfate ions.

Fig. 6 and 7 show the XRD spectra of DMBC700 and soil before and after adsorbing sulfate, respectively. DMBC700 showed a somewhat crystalline structure with a higher mineral content. The presence of quartz, calcite and periclase was confirmed. However, no new mineral peak occurred in the XRD spectrum of DMBC700 after adsorbing sulfate, indicating that DMBC700 and sulfate ions did not react with the newly formed precipitates. The main mineral components of soil were quartz, calcite, kaolinite, bog iron ore and muscovite. A strong and broad peak at $2 \theta=28.07^{\circ}$ indicated the presence of sodium sulfate, which might be due to the reaction between the irregular clay mineral surface and sulfate ions. After sulfate adsorption, a strong $\mathrm{CaSO}_{4}$ peak occurred at $2 \theta=20.54^{\circ}$. Therefore, it was concluded that one of the sulfate ion

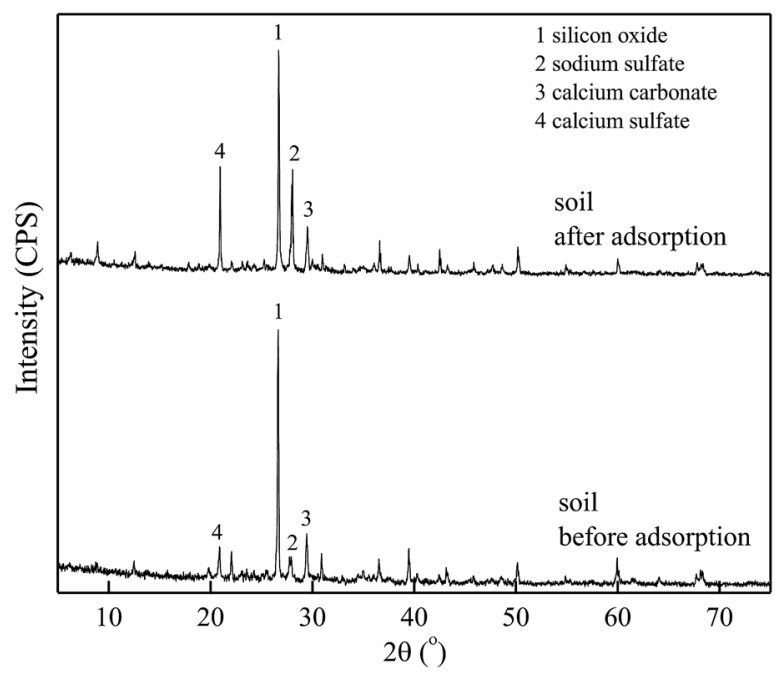

Fig. 7 XRD spectra of soil before and after adsorption. adsorptions could be attributed to the formation of poorly soluble calcium sulfate. As a calcareous soil, the carbonate content in light sierozem is high. Sulfate ions could thus react with the calcium ions in calcium carbonate to form a precipitate. ${ }^{23}$

\section{Conclusions}

The kinetics of sulfate adsorption onto DMBC700, soil and soil with DMBC700 could be described using a pseudo-second-order model, while the isotherms could fit well with Langmuir and Freundlich models. On the basis of the results of the effect of $\mathrm{pH}$ values on adsorption and FTIR and XRD analyses before and after adsorption, it was shown that the main driving force of sulfate adsorption onto DMBC700 was the electrostatic interaction; moreover, for sulfate adsorption onto light sierozem, both electrostatic interaction and formation of poorly soluble $\mathrm{CaSO}_{4}$ were the major forces. However, DMBC700 amendment did not enhance the adsorption capacity of light sierozem for sulfate ions.

\section{Conflicts of interest}

There are no conflicts to declare.

\section{Acknowledgements}

This research was financially supported by the National Natural Science Foundation of China (21467013, 21167007, 51766008).

\section{Notes and references}

1 E. Frossard, E. K. Bünemann, A. Oberson and M. A. Kertesz, Phosphorus and Sulfur in Soil, CRC Press, 2012.

2 J. Lehmann, Nature, 2007, 447, 143-144.

3 B. Yousaf, G. Liu, Q. Abbas, M. U. Ali, R. Wang, R. Ahmed, C. Wang, M. I. Al-Wabel and A. R. A. Usman, J. Cleaner Prod., 2018, 195, 458-469.

4 J. Lehmann and S. Joseph, Biochar for Environmental Management: Science and Technology, Earthscan, London, 2009.

5 Z. M. Lan, C. R. Chen, M. R. Rashti, H. Yang and D. K. Zhang, Sci. Total Environ., 2017, 576, 559-571.

6 F. Reverchon, R. C. Flicker, H. Yang, G. Yan, Z. Xu, C. Chen, S. H. Bai and D. Zhang, Biol. Fertil. Soils, 2014, 50, 275-283.

7 F. Reverchon, H. Yang, T. Y. Ho, G. Yan, J. Wang, Z. Xu, C. Chen and D. Zhang, Environ. Sci. Pollut. Res., 2015, 22, 2138-2144.

8 L. D. Hafshejani, A. Hooshmand, A. A. Naseri, A. S. Mohammadi, F. Abbasi and A. Bhatnagar, Ecol. Eng., 2016, 95, 101-111.

9 K.-W. Jung, K. Kim, T.-U. Jeong and K.-H. Ahn, Bioresour. Technol., 2016, 200, 1024-1028.

10 C. A. Takaya, L. A. Fletcher, S. Singh, K. U. Anyikude and A. B. Ross, Chemosphere, 2016, 145, 518-527.

11 P. A. Trazzi, J. J. Leahy, M. H. B. Hayes and W. Kwapinski, J. Environ. Chem. Eng., 2016, 4, 37-46. 
12 Q. Chen, J. Qin, P. Sun, Z. Cheng and G. Shen, J. Cleaner Prod., 2018, 172, 2009-2018.

13 S. Li, V. Barreto, R. Li, G. Chen and Y. P. Hsieh, J. Anal. Appl. Pyrolysis, 2018, 133, 136-146.

14 Y. Liu, Z.-Q. Zhu, X.-S. He, C. Yang, Y.-Q. Du, Y.-D. Huang, P. Su, S. Wang, X.-X. Zheng and Y.-J. Xue, Chemosphere, 2018, 207, 267-277.

15 S. E. Hale, V. Alling, V. Martinsen, J. Mulder, G. D. Breedveld and G. Cornelissen, Chemosphere, 2013, 91, 1612-1619.

16 C. C. Hollister, J. J. Bisogni and J. Lehmann, J. Environ. Qual., 2013, 42, 137-144.

17 J. Jiang, M. Yuan, R. Xu and D. L. Bish, Soil Tillage Res., 2015, 146, 139-147.

18 J. Yang, H. Li, D. Zhang, M. Wu and B. Pan, Sci. Total Environ., 2017, 592, 758-765.
19 B. Zhao, X. Nan, H. Xu, T. Zhang and F. Ma, J. Environ. Manage., 2017, 201, 309-314.

20 Z. L. Ni, F. B. Tang, M. H. Qu and R. H. Mo, Chin. J. Soil Sci., 2012, 43, 1136-1138.

21 Z. Wang, E. Nie, J. Li, M. Yang, Y. Zhao, X. Luo and Z. Zheng, Environ. Sci. Pollut. Res., 2011, 19, 2908-2917.

22 Y. Yao, B. Gao, J. Chen and L. Yang, Environ. Sci. Technol., 2013, 47, 8700-8708.

23 X. Li, Soil Chemistry, High Education Press, Beijing, 2001.

24 Q. Abbas, G. Liu, B. Yousaf, M. U. Ali, H. Ullah, M. A. M. Munir and R. Liu, J. Anal. Appl. Pyrolysis, 2018, 134, 281-292.

25 Z. Cao, C. Meng and Z. Hu, Sulfur in Agriculture and Environment of China, Science Press, Beijing, 2011.

26 F. F. Ma, B. W. Zhao, J. R. Diao, J. K. Zhong and A. B. Li, Environ. Sci., 2015, 36, 1678-1685. 